\title{
Extended iso geometry analysis of crack propagation
}

- Truong Tich Thien

- Tran Kim Bang

- Nguyen Duy Khuong

- Nguyen Ngoc Minh

- Nguyen Thanh Nha

Ho Chi Minh city University of Technology, VNU-HCM

(Manuscript Received on August 01 ${ }^{\text {st }}$, 2015, Manuscript Revised August 27 ${ }^{\text {th }}$, 2015)

\section{ABSTRACT:}

The purpose of this paper is simulating the crack propagation in steel structures with isogeometry analysis (IGA). In this method, CAD model is integrated into the $C A E$ model by using non uniform rational $B$-Splines (NURBS) function. Crack propagation in isotroptic linear elastic material will be presented. The numerical example is a rectangular plate assumed to be plane strain condition with an edge crack under uniform shear loading. The obtained

Key words: crack propagation, isogeometry analysis, extended, NURBS.

\section{INTRODUCTION}

In simulating the crack growth problems with arbitrary paths, the FEM has encountered many difficulties because the finite element mesh must be re-meshing after each increment of growthing cracks. To overcome these difficulties, the extened finite element method (Moes et al.1999) was developed to solve crack growth problems. XFEM is developed based on Partition of Unity Finite Element Method (PUFEM) [1]. Belytschko và Black (1999) [2] introduced a minimal remeshing method for crack propagation problems. Moës (1999) [3] improved this method. Dolbow (1999) [4] applied XFEM to solve crack problem in shell structures. results are investigated and compared with analytical method and reference solutions. Very good agreements on the solutions are found. It is showed that isogometry analysis is better than standard finite element method in modeling and simulating. Consequently, isogometry analysis is an effective numerical method in future, especially when solving the crack propagation problems.

\section{Page 76}

In recent years, Isogeometric Analysis IGA has been successfully developed by Hughes at Institute for Computational Engineering and Sciences [5, 6], The University of Texas (USA). The main idea of this method is the use of NURBS basis functions to build CAD geometry for modeling, the concept is similar to the finite element method (FEM). The difference is in FEM, Lagrange shape functions is used while IGA using NURBS shape functions to approximate the problem domain. There are several articles have demonstrated the approximate model discontinuities by using NURBS is better FEM shape function [7, 8] 
The combination XFEM and IGA opens a modern approaching in the field of computational fracture mechanics, that is Extended Isogeometric Analysis - XIGA. XIGA inherited the advantages of XFEM and IGA, fully capable of solving some complex crack propagation problem without re-meshing. On the other hand, the complex geometry of objects can be modeled with a few of elements, so the calculation time can be reduced significantly.

\section{FUNDAMENTALS OF NURBS AND} XIGA

$$
N_{i, p}(\xi)=\frac{\xi-\xi_{i}}{\xi_{i+p}-\xi_{i}} N_{i, p-1}(\xi)+\frac{\xi_{i+p+1}-\xi}{\xi_{i+p+1}-\xi_{i+1}} N_{i+1, p-1}(\xi)
$$



Figure 1. B-Spline basis functions of order $p=2$

Figure 1 shows the B-Spline basis functions of order $\mathrm{p}=2$ with open knot vector and $\boldsymbol{\Xi}=\{0,0,0,1,2,3,4,4,5,5,5\}$.

\subsection{B-Spline curve}

Given $n$ basis functions corresponding to the knot vector $\boldsymbol{\Xi}=\left\{\xi_{1}, \xi_{2}, \mathrm{~K}, \xi_{n+p+1}\right\}$ and a set of control points $\left\{\mathbf{B}_{i}\right\}, i=1,2, \ldots, n$, the B-Spline



(a) The curve and control points curve is given by:

$$
\mathbf{C}(\xi)=\sum_{i=1}^{n} N_{i, p}(\xi) \mathbf{B}_{i}
$$

with $N_{i, p}(\xi)$ is the B-Spline basis functions of order $p, \mathbf{B}_{i}$ is $i$ th control point. Figure 2 show B-Spline curve of order $\mathrm{p}=2$ corresponding to the knot vector $\boldsymbol{\Xi}=\{0,0,0,1,2,3,4,4,5,5,5\}$.

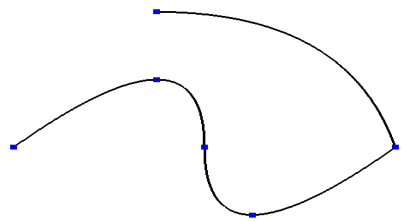

(b) The curve and mesh created by knot points

Figure 2. B-Spline curve of order $\mathrm{p}=2$ 


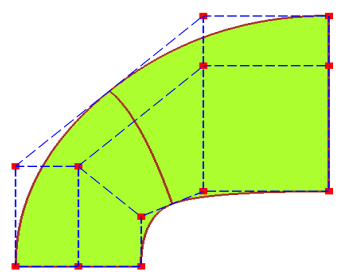

Figure 3. The control net and mesh for the biquadratic B-Spline surface

Given a set of control points, call a control net $\left\{\mathbf{B}_{i, j}\right\}, i=1,2, \ldots, n, j=1,2, \ldots, m$, polynomial orders $\mathrm{p}$ and $\mathrm{q}, \quad$ knot vectors $\boldsymbol{\Xi}=\left\{\xi_{1}, \xi_{2}, \mathrm{~K}, \xi_{n+p+1}\right\}$ và $\mathbf{H}=\left\{\xi_{1}, \xi_{2}, \mathrm{~K}, \xi_{n+p+1}\right\}$, the B-Spline surface is thus defined by:

$$
\mathbf{S}(\xi, \eta)=\sum_{i=1}^{n} \sum_{j=1}^{m} N_{i, p}(\xi) M_{j, q}(\eta) \mathbf{B}_{i, j}
$$

Figure 3 depicts biquadratic B-Spline surface with knot vector $\mathbf{\Xi}=\{0,0,0,0.5,1,1,1\} \quad$ và $\mathbf{H}=\{0,0,0,1,1,1\}$.

\subsection{NURBS geometry}

NURBS basis is then given as follows:

$$
R_{i}^{p}(\xi)=\frac{N_{i, p}(\xi) w_{i}}{\sum_{i=1}^{n} N_{i, p}(\xi) w_{i}}
$$

with $N_{i, p}$ the B-Spline basis functions and $w_{i}$ is ith weight function.

The NURBS curve is then defined as in the same manner as the B-spline curves:

$$
\mathbf{C}(\xi)=\sum_{i=1}^{n} R_{i}^{p}(\xi) \mathbf{B}_{i}
$$

The NURBS surfaces are defined as:

$$
\mathbf{S}(\xi, \eta)=\sum_{i=1}^{n} \sum_{j=1}^{m} R_{i, j}^{p, q}(\xi, \eta) \mathbf{B}_{i, j}
$$

Where $R_{i, j}^{p, q}(\xi, \eta)$ are given by:

$$
R_{i, j}^{p, q}(\xi, \eta)=\frac{N_{i, p}(\xi) M_{j, q}(\eta) w_{i, j}}{\sum_{i=1}^{n} \sum_{j=1}^{m} N_{i, p}(\xi) M_{j, q}(\eta) w_{i, j}}
$$

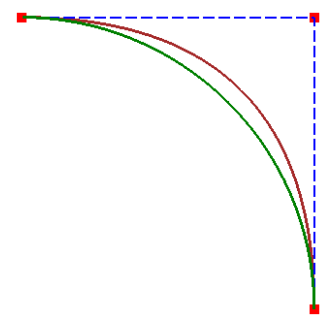

Figure 4. Example of a NURBS curve for constructing a quarter of a circle

\subsection{Finite element analysis with NURBS}

Most often IGA input involves knot vectors and control points data The physical domain is denoted by $\Omega$ and the parametric domain by $\hat{\Omega}$. The mapping from the parametric domain $\hat{\Omega}$ to the physical domain $\Omega$ is given by:

$$
\mathbf{x}=\sum_{i=1}^{n} N_{i}(\xi) \mathbf{B}_{i}
$$

Where $N_{i}(\xi)$ refers to either the univariate NURBS basis function if $\Omega$ is a curve or the bivariate NURBS basis function in case $\Omega$ is a surface.

In an isoparametric formulation, the displacement field is approximated by the same shape functions: 


$$
\mathbf{u}(\mathbf{x})=\sum_{i=1}^{n} N_{i}(\xi) \mathbf{u}_{i}
$$

where $\mathbf{u}_{i}$ denotes the value of the displacement field at the control point $\mathbf{B}_{i}$.

\subsection{Extended isogometry analysis} (XIGA)

General form of the XFEM for modeling the crack is given by

$$
\begin{aligned}
& \boldsymbol{u}^{h}(\boldsymbol{x})=\sum_{i \in I} N_{i} \boldsymbol{u}_{i}+\sum_{j \in J} \boldsymbol{b}_{j} N_{j}^{*} S(\boldsymbol{x})+ \\
& +\sum_{k \in K} N_{k}^{*} \sum_{l=1}^{4}\left(\boldsymbol{c}_{k}^{l} F^{l}(\boldsymbol{x})\right)
\end{aligned}
$$

where $\mathbf{u}^{\mathrm{h}}(\mathbf{x})$ is the approximated function of the displacement field; $\mathrm{N}$ is the shape function computed at the control points; $\mathbf{u}, \mathbf{b}, \mathbf{c}$ respectively, are the unknown degrees of freedom corresponding to the sets named as I, J and $\mathrm{K} . \mathrm{I}$ is the set of total nodes in the problem domain, whereas $\mathrm{J}$ is the set of nodes enriched by the sign function $\mathrm{S}(\mathbf{x})$

$$
S(\boldsymbol{x})=\left\{\begin{array}{c}
1 \text { for } \psi(\boldsymbol{x}, t)>0 \\
-1 \text { for } \psi(\boldsymbol{x}, t)<0
\end{array}\right.
$$

wherw $\Psi(\mathbf{x}, \mathrm{t})$ is the level set function

Set $\mathrm{K}$ is the set of nodes enriched by the tip enrichments, also known as branch functions in many literatures.

$$
\begin{aligned}
& F^{1}(r, \theta)=\sqrt{r} \sin \left(\frac{\theta}{2}\right), \\
& F^{2}(r, \theta)=\sqrt{r} \cos \left(\frac{\theta}{2}\right), \\
& F^{3}(r, \theta)=\sqrt{r} \sin \left(\frac{\theta}{2}\right) \sin (\theta), \\
& F^{4}(r, \theta)=\sqrt{r} \cos \left(\frac{\theta}{2}\right) \sin (\theta)
\end{aligned}
$$

where $(r, \theta)$ are the local polar coordinates defined at the crack tip.

In NURBS-based XFEM, the sets I, J and $\mathrm{K}$ are also associated with control points, correspondingly.

\subsection{The level set method}

According to $[10,11]$, the level set method is use to detect the discontinuous surfaces. As sketched in Figure 5, the crack is considered to be the zero level set of $\Psi$.

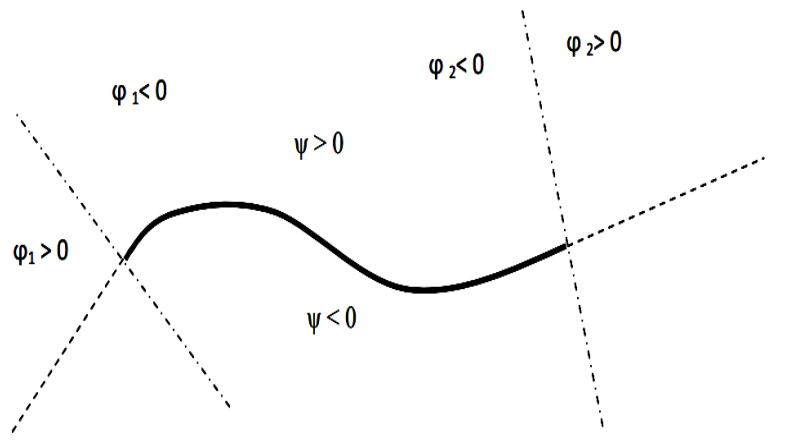

Figure 5. Construction of initial level set functions

where both $\varphi_{1}<0$ and $\varphi_{2}<0$ in case of an interior crack or where $\varphi_{1}<0$ in case of an edge crack. In cases that more than one crack tip exists, it is convenient todefine a single function $\varphi(\mathbf{x}, \mathrm{t})$ to unify all the functions $\varphi_{i}$

$$
\varphi(x, t)=\max \left(\varphi_{i}\right)
$$

Within the framework of crack growth problems, the level set must be updated appropriately, but only nodes locally close to the crack are updated. In addition, it is assumed that 
once a part of a crack has formed, that part will be fixed (Stolarska et al. (2001) [5]).

The evolution of the crack is modeled by appropriately updating the functions level set $\psi$ and $\varphi$ then reconstructing the $\varphi$ function. In each step, the incremental length and the angle of the propagating direction, $\theta_{c}$ are known. The displacement of the crack tip is given by the vector

$$
\boldsymbol{F}=\left(F_{x}, F_{y}\right)=\boldsymbol{x}_{i}^{t i p, n+1}-\boldsymbol{x}_{i}^{t i p, \mathrm{n}}
$$

where $x_{i}{ }^{\text {tip,n+1 }}$ is the current crack tip (step $\mathrm{n}+1)$ and $\mathrm{x}_{\mathrm{i}}{ }^{\mathrm{tip}, \mathrm{n}}=\left(\mathrm{x}_{\mathrm{i}}, \mathrm{y}_{\mathrm{i}}\right)$ is the crack tip at step $\mathrm{n}$. Let the values of $\psi$ and $\varphi$ at step $n$ be $\psi^{\mathrm{n}}$ và $\varphi^{\mathrm{n}}$. The updated values of $\psi$ and $\varphi, \psi^{\mathrm{n}+1}$ and $\varphi^{\mathrm{n}+\mathrm{at}} \mathrm{n}+1$ are determined by the following algorithm [5]:

(1) $\varphi_{i}^{\mathrm{n}+1}$ is updated at each step.

(2) $\mathbf{F}$ is not necessarily orthogonal to the zero level set $\varphi_{\mathrm{i}}{ }^{\mathrm{n}}$. Thus $\varphi_{i}^{n}$ is rotated to become $\overline{\varphi_{i}}$ so that $\mathbf{F}$ is orthogonal

$$
\bar{\varphi}_{i}=\left(x-x_{i}\right) \frac{F_{x}}{\|\boldsymbol{F}\|}+\left(y-y_{i}\right) \frac{F_{y}}{\|\boldsymbol{F}\|}
$$

(3) The crack is extended by computing new values of $\psi^{\mathrm{n}+1}$ only where $\overline{\varphi_{i}}>0$

(4) Once all $\varphi_{\mathrm{i}}^{\mathrm{n}+1}$ corresponding to a crack are updated, $\varphi^{\mathrm{n}+1}$ is updated using (14)

For the XIGA, the values at control points are also stored. The values at other points within a given element are approximated from the values of the control points that support the given element as follows:

$\psi(\boldsymbol{x})=\sum_{i=1}^{N_{c p}} N_{i} \psi_{i}$

where $\mathrm{N}_{\mathrm{cp}}$ is the number of control points which support the element. The other level set functions are also approximated by using the same form of (17).
For the NURBS-based XFEM, an element is determined to be split element, i.e. discontinuous-enriched, or tip element, i.e. tipenriched, from the nodal values of $\psi$ and $\varphi$. The enrichment has to be chosen for the control points. The values of enrichment function in (11) are computed at the control points.

\subsection{Maximum circumferential stress criterion}

The maximum circumferential stress criterion states that the crack will propagate from its tip in a direction assigning by an angle $\theta_{c}$ where the circumferential stress $\sigma_{\theta \theta}$ is maximum $[3,5]$

$\theta_{c}=2 \arctan \left(\frac{1}{4}\left(\frac{K_{I}}{K_{I I}} \pm \sqrt{\left(\frac{K_{I}}{K_{I I}}\right)^{2}+8}\right)\right)$

The stress intensity factors are computed using the interaction integral [3].

\subsection{Interaction integral}

Interaction integral for states 1 and 2 is given as follow

$$
\begin{array}{r}
I^{(1,2)}=\int_{\Gamma}\left[W^{(1,2)} \delta_{1 j}-\sigma_{i j}^{(1)} \frac{\partial\left(u_{i}^{(2)}\right)}{\partial x_{1}}\right. \\
\left.-\sigma_{i j}^{(2)} \frac{\partial\left(u_{i}^{(1)}\right)}{\partial x_{1}}\right] n_{j} d \Gamma
\end{array}
$$

With $\mathrm{W}^{(1,2)}$ is the interaction strain energy

\section{NUMERICAL EXAMPLES}

\subsection{Edge crack under uniform shear}

A rectangular plate assumed to be plane strain condition with an edge crack under uniform shear loading $\tau=1 \mathrm{~N} / \mathrm{cm}^{2}$ as depicted in figure 6 . The geometrical parameters are chosen as follows: : $\mathrm{a} / \mathrm{W}=0.5 ; \mathrm{h} / \mathrm{W}=0.5 ; \mathrm{L} / \mathrm{W}=16 / 7, \mathrm{~W}=$ $7 \mathrm{~cm}$. while the material parameters involve Young's modulus $\mathrm{E}=3 \times 10^{7} \mathrm{~N} / \mathrm{cm}^{2}$ and Poisson's ratio $v=0.25$. 


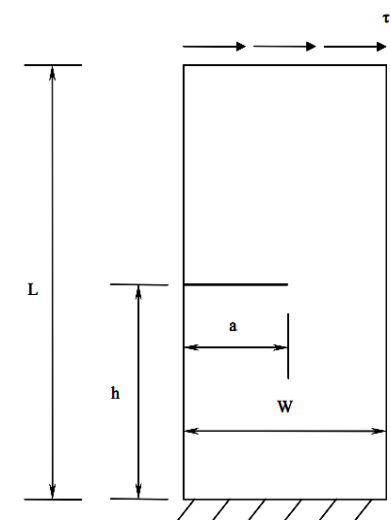

Figure 6. A rectangular plate with an edge crack under uniform shear loading

The reference values of mixed-mode stress intensity factors are given by [3] as follow:

$$
\begin{aligned}
& K_{I}=34 \mathrm{~N} / \mathrm{cm}^{2} \cdot \sqrt{\mathrm{cm}} \\
& K_{I I}=4.55 \mathrm{~N} / \mathrm{cm}^{2} \cdot \sqrt{\mathrm{cm}}
\end{aligned}
$$

Relative error is given by:

$$
\text { Error }=\frac{K^{\text {num }}-K^{\text {exact }}}{K^{\text {exact }}}
$$

The mixed mode stress intensity factors computed for the first-, second- and third-order NURBSbased XFEM are presented in Table 1 with a uniform mesh of $21 \mathrm{x} 4$.

As observed in Table 1, the stress intensity factors of mode I are more accurate when the order of the NURBS functions gets higher, but this behavior does not apply for mode-II. The computational time is increased rapidly when the order of the NURBS functions increases. In practice, the order of the NURBS functions may be chosen in a way dependent on the problems of interest, but second-order could yield a good solution.

Table 1. Mixed mode SIFs computed with 1st, 2nd and 3rd order NURBS-based XFEM

\begin{tabular}{|c|c|c|c|}
\hline & $\begin{array}{c}\text { Stress intensity } \\
\text { factor } \\
\left(N / \mathrm{cm}^{2} \cdot \sqrt{\mathrm{cm}}\right)\end{array}$ & $\begin{array}{c}\text { Relative } \\
\text { error }(\%)\end{array}$ & \multirow{2}{*}{ Time (s) } \\
\hline \multirow{2}{*}{$1^{\text {st }}$ order NURBS } & $\mathrm{K}_{\mathrm{I}}=32.977$ & -3.01 & \multirow{2}{*}{20.59} \\
\cline { 2 - 3 } & $\mathrm{K}_{\mathrm{II}}=4.491$ & -1.29 & \multirow{2}{*}{3} \\
\hline \multirow{2}{*}{$2^{\text {nd }}$ order NURBS } & $\mathrm{K}_{\mathrm{I}}=34.401$ & 1.17 & \multirow{2}{*}{33.69} \\
\cline { 2 - 3 } & $\mathrm{K}_{\mathrm{II}}=4.567$ & 0.37 & \multirow{2}{*}{88.68} \\
\hline \multirow{2}{*}{$3^{\text {rd }}$ order NURBS } & $\mathrm{K}_{\mathrm{I}}=34.151$ & 0.44 & \multirow{2}{*}{1.10} \\
\cline { 2 - 3 } & $\mathrm{K}_{\mathrm{II}}=4.600$ & \multicolumn{2}{|c|}{} \\
\hline
\end{tabular}



Figure 7. Stress fields of the horizontal edge crack specimen $\left(31 \times 61\right.$ elements, $2^{\text {nd }}$ order NURBS $)$ 


\subsection{Edge crack propagation under} uniform shear

A rectangular plate assumed to be plane strain condition with an edge crack under uniform shear loading $\tau=1 \mathrm{~N} / \mathrm{m}^{2}$. The geometrical parameters are chosen as depicted in Fig. 8. The unit of length is the metre $(\mathrm{m})$ while the material parameters involve Young's modulus $\mathrm{E}=30 \times 10^{6}$ $\mathrm{N} / \mathrm{m}^{2}$ and Poisson's ratio $v=0.25$.

We check the accuracy of the XIGA by comparing the obtained solutions with those given in previous work [12] (Scale boundary finite element method - SBFEM). The compared results show a good agreement between two methods. Additionally, The crack paths obtained by two

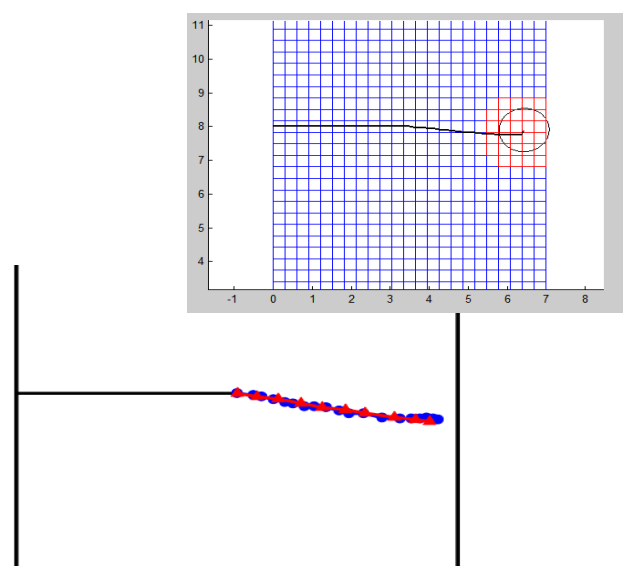

XIGA method are shown in Figs. 9, respectively, which shows a good agreement as expected.

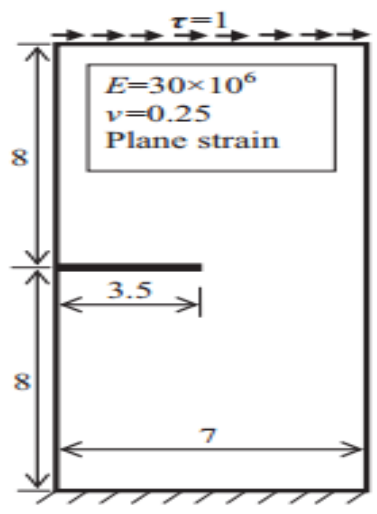

Figure 8. A rectangular plate with an edge crack under uniform shear loading

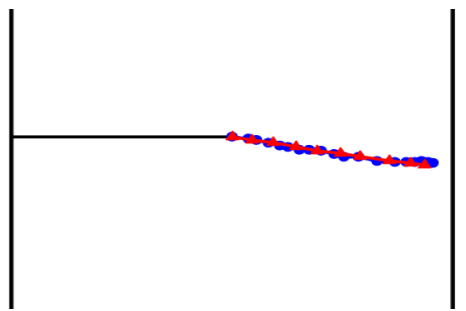

\section{CONCLUSIONS}

We have applied the XIGA to solve the crack propagation problems. Several numerical examples are considered. The obtained results in stress intensity factor and crack path are investigated and compared with other numerical methods such as XFEM and scale boundary finite element method. Very good agreements on the solutions are found. It is showed that the XIGA is suitable for solving complex crack propagation problems. Consequently, isogometry analysis is an effective numerical method in future.

Acknowledgments: This research is funded by Vietnam National University HoChiMinh City (VNU-HCM) under grant number C2014-20-05 


\section{Mô phỏng sự lan truyền vết nứt bằng phân tích đẳng hình học mở rộng}

- Trương Tích Thiện

- Trần Kim Bằng

- Nguyễn Duy Khương

- Nguyễn Ngọc Minh

- Nguyễn Thanh Nhã

Trường Đại học Bách khoa, ĐHQG-HCM

\section{TÓM TÁ́T:}

Bài báo sử dụng phân tích đẳng hình học mở rộng để mô phỏng quá trình lan truyền vết nứt. Ý tưởng chính là dùng các hàm co' sở "non uniform rational $B$ Splines (NURBS)" cho cả việc mô hình hình học lẫn đưa vào lời giải phân tích số. Bài báo này xét đến sự lan truyền vết nứt trong kết cấu có vật liệu đẳng hướng như là kim loại. Dạng bài toán được đề cập trong đây là bài toán tấm hình chữ nhật có vết nứt ở cạnh và tấm hình chữ $L$ có vết nứt tại góc. Kết quả số thu được đem so sánh với lời giải giải tích và một vài công bố khác. Bài báo có thể chứng minh được những ưu điểm của phân tích đẳng hình học mở rộng trong việc mô hình và tính toán số nếu so với phương pháp truyền thống thông dụng là phương pháp phần tử hữu hạn. Vì thế, phân tích đẳng hình học là một công cụ hữu hiệu dùng để tính toán số trong tương lai, đặc biệt là bài toán lan truyền vết nứt trong kim loai.

Từ khóa: nưt, lan truyền nưt, phân tích đẳng hình học, mở rộng, NURBS

\section{REFERENCES}

[1]. Melenk, J.M. and I. Babuska, The Partition of Unity Finite Element Method: Basic Theory and Applications. Seminar fur Angewandte Mathematik, Eidgenossische Technische Hochschule. Research Report No. 96-01, 1996.

[2]. Belytschko, T. and T. Black, Elastic crack growth in finite elements with minimal remeshing. Computer Methods in Applied Mechanics and Engineering, 45(5): p. 601620, 1999.

[3]. Moes, N., J. Dolbow, and T. Belytschko, A finite element method for crack growth without remeshing. Journal for Numerical
Methods in Engineering, 46(1): p. 131-150, 1999.

[4]. Dolbow, J.E., An Extended Finite Element Method with Discontinuous Enrichment for Applied Mechanics, in Theoretical and Applied Mechanics, Northwestern University: American, 1999.

[5]. Hughes, T.J.R., J.A. Cottrell, and Y.

Bazilevs, Isogeometric analysis: $C A D$, finite elements, NURBS, exact geometry and mesh refinement. Computer Methods in Applied Mechanics and Engineering, 194(39-41): p. 4135-4195, 2005. 
[6]. Cottrell J. Austin, T.J.R.H., Bazilevs Yuri, Isogeometric Analysis: Toward Integration of CAD and FEA, Wiley, 2009.

[7]. Verhoosel, C.V., et al., An isogeometric analysis approach to gradient damage models. International Journal for Numerical Methods in Engineering, 86(1): p. 115-134, 2011.

[8]. Luycker, E.D., et al., X-FEM in isogeometric analysis for linear fracture mechanics. International Journal for Numerical Methods in Engineering, 87(6): p. 541-565, 2011.

[9]. Piegl, L. and W. Tiller, The NURBS Book, Springer, 1997.

[10]. Ventura, G., J.X. Xu, and T. Belytschko, $A$ vector level set method and new discontinuity approximations for crack growth by EFG. International Journal for Numerical Methods in Engineering, 54: p. 923-944, 2002.

[11]. Ventura, G., E. Budyn, and T. Belytschko, Vector level sets for description of propagating cracks in finite elements. International Journal for Numerical Methods in Engineering, 58: p. 1571-1592, 2003.

[12]. Yang Z.J., Wang X.F., Yin D.S., Zhang Ch, A non-matching finite element-scaled boundary finite element coupledmethod for linear elastic crack propagation modelling. Computers and Structures 153 p. 126-136, 2015. 